\title{
Experimental transmission of an autosomal dominant spongiform encephalopathy: Does the infectious agent originate in the human genome?
}

\author{
H F BAKER, R M RIDLEY, T J CROW
}

\begin{abstract}
Marmosets inoculated intracerebrally with brain tissue from a woman with Gerstmann-Straussler syndrome (an autosomal dominant dementia associated with spongiform change and amyloid deposition) developed an encephalopathy indistinguishable from that seen in marmosets inoculated with brain tissue from a typical case of Creutzfeldt-Jakob disease. As in Huntington's disease, in the pedigree of the patient with GerstmannStraussler syndrome women who subsequently developed the illness had increased fecundity.

The pathogen in human transmissible dementia may arise from a sequence (which itself sometimes confers a selective advantage) located within the human genome.
\end{abstract}

\section{Introduction}

Creutzfeldt-Jakob disease is a rare and usually sporadic presenile dementia with a wide geographical distribution. The mean age at onset is 57 years, and death often occurs within 12 months. ${ }^{1}$ Postmortem findings include widespread vacuolation (spongiform encephalopathy), astrocytic hyperplasia, and neuronal loss. The disease shares several fundamental features with kuru and scrapie, including neuronal vacuolation, apparent absence of an immune response, ${ }^{2}$ and transmissibility to animals by intracerebral injection of brain tissue. ${ }^{3}$ The agents responsible for these diseases resist inactivation by formalin, ${ }^{4}$ heat, and ionising radiation ${ }^{5}$ and are remarkably insensitive to nucleases, although infectivity is reduced by procedures which hydrolyse

\footnotetext{
Division of Psychiatry, Clinical Research Centre, Harrow, Middlesex HA1 3UJ

H F BAKER, MSC, chief research officer

R M RIDLEY, PHD, scientific officer

T J CROW, PHD, FRCPSYCH, head of division

Correspondence to: Dr T J Crow.
}

or modify proteins. It has been proposed that these "unconventional viruses" include no nucleic acid but are a novel form of infectious proteinaceous particle or "prion."”

Of unusual interest are the familial forms of CreutzfeldtJakob disease. Although typically the disease is sporadic and geographical clustering is rare, in $10-15 \%$ of cases two or more members of one family are affected, and in many of these families the disease may be seen to occur in an autosomal dominant pattern. ${ }^{1}$ In some families the disease has persisted through at least four generations with 10 or more affected members. ' Another familial spongiform encephalopathy (the Gerstmann-Straussler syndrome) differs from familial Creutzfeldt-Jakob disease in that the progression of the disease is slower (with a mean duration of illness of five years), age at death is younger, spongiform change in the brain is less severe, and amyloid plaques are common. ${ }^{8}$

We report transmission to the common marmoset of spongiform encephalopathy from a patient who suffered from Gerstmann-Straussler syndrome and from a sporadic case of Creutzfeldt-Jakob disease. We have analysed the pedigree of the patient with Gerstmann-Straussler syndrome and considered the implications of mendelian occurrence for the nature of the agent.

\section{Materials and methods}

A sample of frontal cortex was taken at necropsy from a 71 year old woman (case 1) who died after an eight week illness starting with unsteadiness of gait and vertigo and progressing (with a brief period in which myoclonus was seen) to cerebellar ataxia, spasticity, and dementia, with periodic electroencephalographic complexes characteristic of Creutzfeldt-Jakob disease. There was no family history of neurological disease. Examination of the brain showed widespread neuronal depletion, gliosis, and spongiform degeneration, most pronounced in occipital cortex but present also in other regions of cortex, thalamus, and cerebellum. Cortical tissue was also taken from a 46 year old woman (case 2) who had died six years after the onset of an illness which presented with paraesthesiae in both thighs and unsteadiness of gait and progressed slowly with episodes of diplopia, slurring of speech, and motor clumsiness to cerebellar ataxia and dysarthria. In the last year of the illness she suffered increasing 
intellectual loss and cranial nerve symptoms. Examination of the brain (Professor L W Duchen) showed amyloid deposition and spongiform encephalopathy. This patient was a member of a large kinship in which a polymorphic neurological syndrome occurred in an autosomal dominant pattern (see below).

Inoculum was prepared as a $10 \% \mathrm{wt} / \mathrm{vol}$ homogenate of brain tissue in $0.85 \%$ sterile saline. A $50 \mu 1$ sample was injected into six sites in each animal (a total of $0.3 \mathrm{ml}$ ) under pentobarbitone anaesthesia. Injections were made stereotaxically into the caudate, hippocampus, and parietal cortex in the left hemisphere and the nucleus accumbens, amygdala, and parietal cortex in the right hemisphere in order to avoid bilaterally symmetrical damage. Each animal was also injected intraperitoneally with $0.7 \mathrm{ml}$ inoculum. Four consecutive sets of marmoset twins born to the same parent animals over two years were inoculated (see table I). One member of each set of twins was injected once daily for four days (beginning the day before the brain inoculation) with $0.5 \mathrm{ml}$ ammonium tungstoantimoniate $(10 \mathrm{mg} / \mathrm{ml}$ intraperitoneally). This drug (HPA 23) has been shown to be effective antimoniate was ineffective in impeding the disease since in each case the animal injected with this agent reached this condition before its twin (table I). Brains were removed and divided midsagitally. In each case one hemibrain was immersion fixed in $10 \%$ formol saline while the other was deep frozen for second passage. Haematoxylin and eosin stained sections showed the presence of spongiform change, most pronounced in the basal ganglia and thalamus, in each of the eight animals. In no case was amyloid deposition detected. The lesions were similar in animals inoculated with material from cases 1 and 2.

\section{PEDIGREE OF CASE 2}

The figure shows the family tree of case 2 (subject IV 2). Eighteen affected members had been described in four generations and there was evidence that further members had died of neurological disease in earlier generations. ${ }^{12}$ In five cases the brains were examined

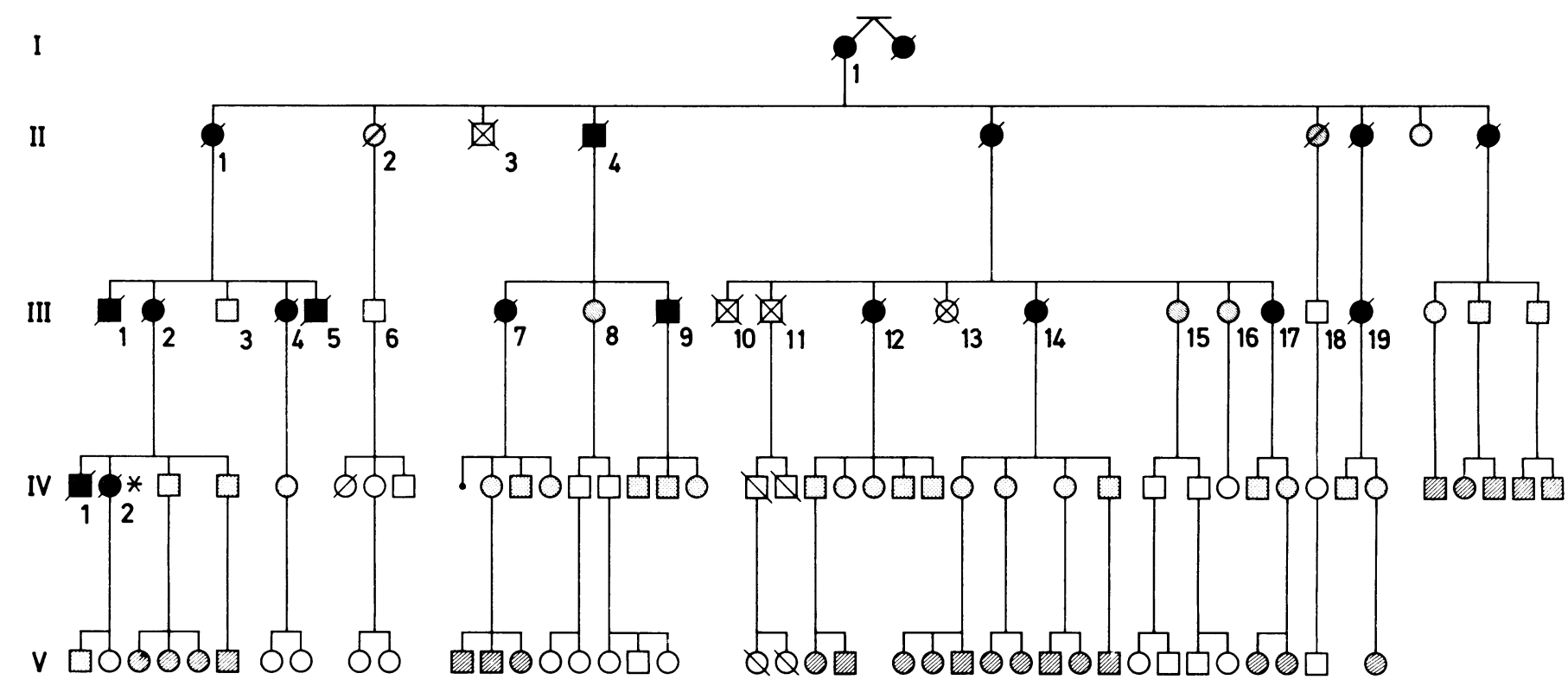

* Case 2

Family tree of case 2 (subject IV 2) showing all descendants of subject I 1, previously described.12 13 Data on recent extensions were corroborated by several family members. Twin sister of subject $I 1$ was believed to have been affected but did not marry and therefore probably did not have children. Total number of affected members (including subject I 1 ) is currently 18. Disease was never seen to skip generations. Among children and grandchildren of subject I 1 the offspring of affected parents comprised 15 affected, seven unaffected, three still at risk, and four who could not be classified because they died young. This was consistent with autosomal dominant transmission with complete penetrance. Affected. $\mathbb{Q}$ Unaffected, age $>55$. $\square$ At primary (50\%) risk. At secondary $(25 \%)$ risk. $\square$ At no risk. / Deceased. \ Could not be classified (died young or parent died young).

against some conventional viruses 910 and if administered at the time of inoculation impedes the course of scrapie in mice. ${ }^{11}$ All animals were observed daily and any peculiarity in behaviour noted. No other animals were inoculated at that time with brain material from any other source. The yearly adult mortality from natural causes was less than $5 \%$ in this colony.

\section{Results}

All animals recovered well from the inoculation and were behaving normally within two to three days. Thereafter they remained physically well for 12 months. From 12 months onwards most animals were dishevelled and noticeably inactive, spending an increasing amount of time sleeping during daylight hours. The first neurological signs were minor loss of balance and a need to correct for overshooting when jumping on to a perch. The final stage of illness lasting from one week to four months consisted of profound weight loss (despite good appetite), a tendency to eat from the floor of the cage rather than from the hands, an ataxic gait, and profuse salivation. Muscle fasciculations were seen occasionally but tremor was absent. Animals were killed by injection of pentobarbitone when they appeared to be deteriorating rapidly and death was imminent. Ammonium tungsto- histopathologically. All showed amyloid deposition and varying degrees of spongiform encephalopathy. ${ }^{12} 13$ Statistical analysis of fecundity was conducted on subject $I 1$ and her descendants using the method of Hill and Peto. ${ }^{14}$ Table II shows that while all men and unaffected women had about the same number of children, women who subsequently became affected had a greater number of children, the larger proportion of whom were daughters. These tendencies

TABLE I-Survival times after inoculation (inoculum I from patient with rapid classical Creutzfeldt-fakob disease (case 1); inoculum II from patient with slowly progressive Gerstmann-Straussler syndrome (case 2))

\begin{tabular}{ccccc}
\hline $\begin{array}{c}\text { Marmoset } \\
\text { twins }\end{array}$ & Animal & Inoculum & $\begin{array}{c}\text { Age at inoculation } \\
\text { (months) }\end{array}$ & $\begin{array}{c}\text { Survival time } \\
\text { (months) }\end{array}$ \\
\hline & $\left\{1^{*}\right.$ & I & 11 & 20 \\
A & $\left\{3^{*}\right.$ & I & 11 & 20.5 \\
B & $\{4$ & I & 10 & 22 \\
C & $\left\{5^{*}\right.$ & II & 10 & 23 \\
6 & II & 14 & 32 \\
D & $\left\{7^{*}\right.$ & II & 21 & 25 \\
8 & II & 21 & 32
\end{tabular}

- Member of twins also injected with ammonium tungstoantimoniate. 
TABLE II-Number of offspring in relation to sex and state of illness of parent

\begin{tabular}{lcrccc}
\hline & & \multicolumn{3}{c}{ No of offspring } & $\begin{array}{c}\text { Mean No of } \\
\text { No of }\end{array}$ \\
\cline { 3 - 5 } & parents & Sons & Daughters & Total & offsping/parent \\
\hline Affected women & 13 & 19 & 30 & 49 & $3 \cdot 8$ \\
Affected men & 5 & 3 & 3 & 6 & $1 \cdot 2$ \\
Unaffected women & 10 & 7 & 5 & 12 & $1 \cdot 2$ \\
Unaffected men & 8 & 4 & 9 & 13 & $1 \cdot 6$ \\
\hline
\end{tabular}

"Unaffected" defined as people aged 55 and symptom free plus people whose parents were $\geqslant 55$ and symptom free. Using method of Hill and Peto 14 it was shown that affected women had had more children than unaffected women $(p=0.002)$ significance.

accounted for the larger number of affected women (13) than men (five) and the greater probability for the disease to be acquired from the mother ( 15 cases) than from the father (three cases). An indication of the increased fitness of those who become affected is provided by the observation that $68^{\prime \prime}$ " of the great grandchildren (whose parents could be assessed) of subject I 1 were at primary risk-that is, 34\% could be expected to develop the disease-while in a simple autosomal dominant disease we should expect only $12.5^{\circ} \mathrm{\%}$ of the great grandchildren of a single patient to be affected. The tendency for women who subsequently become affected to have had more children (with a predominance of girls) than their unaffected siblings or their affected brothers has also been shown for Huntington's disease. ${ }^{15-17}$

\section{Discussion}

The problem posed by these findings is to understand the relation between what is inherited in the family of case 2 and what is transmissible to animals.

Subject III 9 (see figure) died after an illness typical of Creutzfeldt-Jakob disease in symptoms and time course. Examination of the brain showed spongiform change. Brain homogenate from this subject caused a spongiform encephalopathy 20-30 months after intracerebral injection into spider and squirrel monkeys. ${ }^{8}$ Another relative (subject III 19) died after a five year illness, and neuropathological examination showed spongiform encephalopathy and amyloid deposits. Primates inoculated with brain tissue from this subject, however, had not developed disease after more than six years. ${ }^{8}$ The transmission of spongiform encephalopathy from case 2 was therefore the second such transmission from this kinship and confirms that this family suffers from a transmissible dementia associated with amyloid deposition occurring in a mendelian dominant pattern ${ }^{12}$ rather than, as was previously proposed, ${ }^{13}$ an inherited predisposition to neurological disease in general, of which one case happened to be Creutzfeldt-Jakob disease. The similarity of incubation times and neuropathological changes in the animals injected with material from cases 1 and 2 suggests that the Gerstmann-Straussler syndrome is not caused by an agent greatly different from that which causes CreutzfeldtJakob disease. The difference in the duration of symptoms between Creutzfeldt-Jakob disease (less than 12 months) and Gerstmann-Straussler syndrome (about five years) is therefore likely to be related to genetic differences between the patients.

An explanation of the pathogenesis of the transmissible spongiform encephalopathies must be able to account for the epidemiology of sporadic and familial cases of these diseases and for their characteristic ages of onset (Gerstmann-Straussler syndrome 43 (SD 10.7) years, familial Creutzfeldt-Jakob disease 50 (9.7) years, sporadic Creutzfeldt-Jakob disease 57 (9.7) years). ${ }^{78}$ That some cases of the human transmissible dementias are clearly acquired by contamination with infectious tissuefor example, cases of kuru and the known iatrogenic cases of Creutzfeldt-Jakob disease ${ }^{18}$-does not establish that all cases have been similarly acquired. Sporadic Creutzfeldt-Jakob disease has a circumscribed age of onset, whereas no restrictions on age of onset are seen in kuru ${ }^{8}$ and possibly iatrogenic Creutzfeldt-Jakob disease (one patient was only $17^{18}$ ). Hence the characteristic age of onset of sporadic Creutzfeldt-Jakob disease does not reflect an age of increased vulnerability to infection but relates to the pathogenesis in these cases. If all cases of human transmissible dementia are acquired by infection then not only must the age of onset be explained but it must be supposed that (since Creutzfeldt-Jakob disease is rare) either the infectious agent is also rare or the agent is much more widespread than the disease and not normally pathogenic. Those who would argue that the agent is rare must explain how it spreads between spatially and temporally separated cases, why there is so little evidence of outbreaks or clustering, and why in affected families the disease is confined to genetically related members rather than also occurring in those who are conjugally related. If on the contrary the agent is widespread but pathogenic to only a few people then the constitution of those who are susceptible becomes the main focus of interest.

The existence of families in which transmissible dementia occurs in an autosomal dominant pattern implies either that affected family members possess a major allele which confers susceptibility to an agent in the environment ("genetic susceptibility") or that it is the disease itself rather than susceptibility which is inherited ("vertical transmission"). Genetic susceptibility requires that the agent should be widespread, at least within the family circle, since generations are not skipped, and normally non-pathogenic, since only those carrying the allele become affected. Furthermore, since in familial Gerstmann-Straussler syndrome the duration of illness is up to 10 times that in sporadic Creutzfeldt-Jakob disease, ${ }^{8}$ it would have to be accepted that the allele conferring susceptibility in these cases also provides resistance to progression of the disease. For these reasons, and also because it does not explain sporadic cases, the genetic susceptibility hypothesis is implausible. Some form of vertical transmission is much more likely.

Vertical transmission within affected families of an agent which has become integrated in the germ cell line has been suggested: in this case the age at onset might reflect a long incubation starting at birth. ${ }^{17}$ This model requires that horizontal transmission must have occurred in a preceding generation and compels us to consider whether the similar age at onset in sporadic cases is also due to an incubation period beginning in the perinatal period. The latter is difficult to reconcile with the much shorter incubation times typically seen in kuru, iatrogenic Creutzfeldt-Jakob disease, and experimental transmission. Vertical transmission may also occur cytoplasmically or in utero, but in either case the offspring of affected mothers would be more likely to be affected than the offspring of affected fathers. This is unlikely to be the case in the pedigree of case 2, since the excess female transmission was accounted for entirely by the increased fecundity of affected women. The only affected man whose offspring could be fully assessed (subject II 4) had two affected out of three children. This argues against either intrauterine or cytoplasmic transmission.

We therefore suggest that the causative agent of these conditions rather than being an exogenous virus is a product of the human genome which in certain circumstances may be transmitted. In recent years the distinction between genes and viruses has become less obvious than it once was (as shown, for example, by the homology between cellular and viral oncogenes, the endogenous $C$ type viruses, and the structural similarities between viroids and transposable genetic elements). We suggest that there are sequences (which might be described as "virogenes") endogenous to the human genome and normally repressed which in sporadic cases of Creutzfeldt-Jakob disease are derepressed with the consequent production of a transmissible agent. The loss of gene repression may be related to age (and is perhaps comparable to mechanisms concerned in the onset of non-transmissible neurodegenerative diseases which occur in later life in sporadic and occasionally familial forms ${ }^{19}$ ) and a component of "senescence." Families with transmissible dementia occurring in an autosomal dominant pattern may possess a major allele which renders derepression of the virogene 
inevitable, the persistence of such an allele perhaps depending on beneficial effects early in life.

Medawar postulated senescence genes whose effects are deleterious or fatal in later life which persist because they do not decrease and may even increase fitness (reproductive success) at an earlier age. ${ }^{20}$ Huntington's disease is an example of this phenomenon and the same process may have been occurring in the family of case 2, where, despite earlier reproductive advantage, the later deleterious effect may have been the generation of infectious particles from a component or product of the genome.

We are most grateful to Professor L W Duchen, of the Institute of Neurology, Queen Square, London, for performing the necropsy in case 2 and for neuropathological examination of the marmoset brains. We thank Drs A H Tomlinson and F R Wells for supplying tissue from case 1, Dr J T Hughes for a neuropathological report on this patient, Dr R H Kimberlin for supplying HPA 23 and advising on its administration, and Dr E Spokes for neurological assessment of case 2 . We are indebted to the patient in case 2 and those of her relatives who helped in elucidating the family history.

\section{References}

1 Masters CL, Harris JO, Gajdusek DC, Gibbs CJ Jr, Bernoulli C, Asher DM. Creutzfeldt-Jakob disease: patterns of worldwide occurrence and the creutzfeldt-Jakob disease: patterns of worldwide occurrence and the

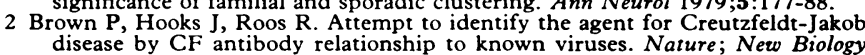
disease by $C F$ an
$1972 ; 235: 149-52$.
3 Gibbs CJ, Gajdusek DC. Experimental subacute spongiform virus encephalopathies in primates and other animals. Science 1973;182:67-8 . formol fixed brain tissue. $N$ Engl $\mathcal{F}$ Med 1976;294:553.

5 Gibbs CJ Jr, Gajdusek DC, Latariet R. Unusual resistance to ionising radiation of the viruses of kuru, Creutzfeldt-Jakob disease and scrapie. Proc Natl Acad Sci USA 1978;75:6268-70.

6 Prusiner SB. Novel proteinaceous infectious particles cause scrapie. Science 1982;216:136-44

7 Masters CL, Gajdusek DC, Gibbs CJ Jr. The familial occurrence of CreutzfeldtJakob disease and Alzheimer's disease. Brain 1981;104:535-58.

from Gerstmann-Straussler syndrome. Brain 1981;104:559-8

9 Jasmin C, Chermann JC, Herve G, Sinoussi FC, Raybaud M. In vivo inhibition antimoniate. Fournal of the National Cancer Institute 1974;53:469-74.

10 Werner G, Jasmin G, Chermann JC. Effect of ammonium-5 tungsto-2-antimoniate on encephalomyocarditis and vesicular stomatitis virus infections in mice. $\mathcal{F}$ Gen Virol 1976;31:59-64.

11 Kimberlin RH, Walker CA. Antiviral compound effective against experimental scrapie. Lancet 1979 ;ii:591-2

12 Adam J, Crow TJ, Duchen LW, Scaravilli F, Spokes E. Familial cerebral amyloidosis an

13 Rosenthal NP, Keesey J Crandall B, Brown WJ. Familial neurological disease associated with spongiform encephalopathy. Arch Neurol 1976;33:252-9.

14 Hill ID, Peto R. Probabilities derived from finite populations. Applied Statistics 1971;20:99-105.

15 Jones MB. Fertility and age of onset in Huntington's chorea. Adv Neurol $1973 ; 1: 171-7$.

16 Marx RN. Huntington's chorea in Minnesota. Adv Neurol 1973;1:237-43.

17 Wallace DC, Parker N. Huntington's chorea in Queensland: the most recent story Adv Neurol 1973;1:223-36.

Bernoulli C, Siegfried J, Baumgartner G, et al. Danger of accidental person to person

19 Ridley RM, Baker HF, Crow TJ. Transmission studies of psychiatric and neurological disease: some reflections on the nature of the agent in transmissible distak $\mathrm{E}$, ed. Viruses, immunity and mental health. New York: Plenum Press (in press). 20 Medawar PB. The uniqueness of the individual. London: Methuen and Co, 1957 :

(Accepted 9 May 1985)

\section{YEARS AGO}

Our correspondent from Valencia writes, under date August 28th: I must begin this short letter by apologising for the questions I put in my last, relating to the seemingly intense susceptibility of healthy returned refugees to be stricken suddenly with cholera on their arrival at their own homes, both in this city and elsewhere. This being a most anxious puzzle to me, I set about earnestly to try to solve it by visiting the houses where these sad disasters occurred. On making every kind of inquiry, I found the same state of affairs in every house. When they abandoned their houses in panic, everything was left therein just as they were: the food on tables, the beds unmade, soiled clothing all about, etc.; all doors and windows and shutters firmly fastened, except the water-closets. After being absent a month or two, when the disease had all but left us, they returned, after a day or days of most fatiguing travel, direct to their own foul abandoned houses, without any precautions as to ventilation and cleanliness. Numbers were cut down in from four to twelve hours. Only yesterday, a patient told me of a wealthy family of eight, friends of his, who returned well after a long journey, and two and a half months' absence from their large house. In thirty-six hours, six had cholera, and four died. I hope I have answered my own question of last week. The Danish steamer Omsk put into this harbour some days ago, having come from Tarragona, the captain allowing only two men on shore. On her arrival here, these same men were found cholera-stricken, and died. Other two, being seized, were sent to hospital here; both recovered, and the ship was ordered to Mahon, to undergo ten days' quarantine. Yesterday, the papers state, four men were attacked on the passage thither. I see, likewise, there is a strong tendency for the disease to return to its well prepared dirty bathing-quarter of Cabañal; six or eight deaths have occurred. I am delighted to inform you that we are going on improving in this city and province in health for three days. For the past eight days, the cholerabulletin has been, "No hay defuncion de colera;" that is, "No deaths from cholera." To-day's cemetery report is, "Fourteen deaths from all causes, and none of these cholera." Hence we are free; so much so, that vessels are now subject to three days' instead of eight days' quarantine. I wish I could report the same good news from all the other provinces; but, on the whole, it is also on the decrease everywhere. On the other hand, the troublesome and prostrating ague is flooding this part of Spain, especially in the "Huerta" and rice-plantations, prostrating in vast numbers the labourers and their masters. In one place, there were ninety harvest-people, and eighty-seven were down with ague. The temperature here has been: maximum for last week, on $23 \mathrm{rd}$ and 24 th, $84 \mathrm{~F}$., min. 79; black bulb, $114^{\circ} \mathrm{F}$; barometer 30 $1 / 10$; wind, E.N.S. While writing now, a "poniente," or westerly inland wind, corresponding to "mistral," "levante," etc., is setting in for the first time this summer, and makes us all, and everything, limp and good for nothing. The harvest reports from all quarters, and about every product, are good. (British Medical fournal 1885;ii:463.)

Professor Corfield chose, as the subject of his address at the anniversary meeting of the Sanitary Institute of Great Britain, the Water-supply of Ancient Roman Cities. He gave a most interesting account of aqueducts erected by Roman engineers, not only at Rome but for certain provincial towns. Rome itself was served by nine aqueducts, and it is a very striking fact, as showing the value which the wise rulers of ancient Rome attached to uncontaminated water, that the third aqueduct, erected over 2,000 years ago by the Prætor Marcius, and hence called the Marcian aqueduct, was no less than 54 miles long. The water-supply of the city was about ten times as great as London receives in proportion to the population, and all the water used for drinking purposes was brought from pure mountain-streams. Small settling-tanks, in four compartments (piscinæ), were interposed, and were so constructed as to be easily cleaned. The channel (specus) of the aqueduct was generally constructed of blocks of stone cemented together and lined with cement; it was roofed over, and, in the earlier aqueducts, was carried entirely underground. But these mighty aqueducts were by no means peculiar to the capital, for wherever the Romans built a city, there they provided for a copious supply of clear water; and Professor Corfield gives a most interesting description of the three aqueducts of Lyons, especially of the great aqueduct built by direction of the Emperor Claudius to supply the imperial palace. The sources of a river were tapped at a point 50 miles from the city, and the water brought through a most irregular country, across valleys, one of which is 300 feet deep and about 1,000 yards wide; the water was taken down the sides of the valleys, and across the streams at the bottom, in eight or ten lead pipes, arranged as inverted siphons. Professor Corfield says of this that it was the most remarkable aqueduct of ancient times, reflecting the greatest possible credit on the Roman engineers, and showing that they well understood the principles of hydraulics. Yet this was only one of three aqueducts erected for the supply of Lyons. We cannot do better than quote the moral of such facts as these in Professor Corfield's own words. "It is thus seen that the ancient Romans spared no pains to obtain a supply of pure water for their cities, and I think it is high time that we followed their example, and went to the trouble and expense of obtaining drinking-water from unimpeachable sources, instead of, as is too of ten the case, taking water which we know perfectly well has been polluted, and then attempting to purify it for domestic purposes." (British Medical fournal 1885;ii:161.) 